Renewable Agriculture and

Food Systems

\section{cambridge.org/raf}

\section{Research Paper}

Cite this article: Amede T, Van den Akker E, Berdel W, Keller C, Tilahun G, Dejen A, Legesse $\mathrm{G}$, Abebe $\mathrm{H}$ (2022). Facilitating livelihoods diversification through flood-based land restoration in pastoral systems of Afar, Ethiopia. Renewable Agriculture and Food Systems 37, S43-S54. https://doi.org/10.1017/ S1742170520000058

Received: 27 July 2019

Revised: 23 November 2019

Accepted: 30 December 2019

First published online: 3 February 2020

Key words:

Bylaws; crop; flood; forage; pastoralists; risk; water-spreading weirs

Author for correspondence:

Tilahun Amede, E-mail: t.amede@cgiar.org

\title{
Facilitating livelihoods diversification through flood-based land restoration in pastoral systems of Afar, Ethiopia
}

\section{Tilahun Amede ${ }^{1}$ (D), Elisabeth Van den Akker $^{2}$, Wolf Berdel ${ }^{2}$, Christina Keller ${ }^{2}$, Gebeyaw Tilahun ${ }^{3}$, Asmare Dejen ${ }^{4}$, Gizachew Legesse ${ }^{2}$ and Hunegnaw Abebe ${ }^{4}$}

${ }^{1}$ International Crops Research Institute for the Semi-Arid Tropics (ICRISAT), Addis Ababa, Ethiopia; ${ }^{2}$ German Development Cooperation (GIZ-Ethiopia), Addis Ababa, Ethiopia; ${ }^{3}$ Woldya University, Woldya, Ethiopia and ${ }^{4}$ Wollo University, Dessie, Ethiopia
(C) The Author(s), 2020. Published by Cambridge University Press. This is an Open Access article, distributed under the terms of the Creative Commons Attribution licence (http://creativecommons.org/licenses/by/4.0/), which permits unrestricted re-use, distribution, and reproduction in any medium, provided the original work is properly cited.

\section{CAMBRIDGE} UNIVERSITY PRESS

\section{Abstract}

The pastoral systems of Eastern Africa have been affected by the alternated incidence of recurrent drought and flood for the last decades, aggravating poverty and local conflicts. We have introduced an innovation to convert floods to productive use using water spreading weirs (WSW) as an entry point to capture and spread the torrential flood emerging in the neighboring highlands into rangelands and crop fields of low-lying pastoral systems in Afar, Ethiopia. The productivity and landscape feature have changed from an abandoned field to a productive landscape within 3 years of intervention. The flood patterns and sediment loads created at least four different crop management zones and productivity levels. Based on moisture and nutrient regimes, we developed land suitability maps for integrating crops and forages fitting to specific niches. The outcome was a fast recovery of landscapes, with $150 \%$ biomass yield increment, increased access to dry season feed and food. These positive outcomes could be attributed to the proper design of weirs, joint planning and execution between pastoralists, researchers and development agents, identification and availing best-fitting varieties for each management zone and developing simple GIS-based parcel level maps to guide development agents and pastoralists. The major 'agents' were community leaders ('Kedoh Abbobati') who keenly debated potential benefits and drawbacks of innovations, enforced customary rules and byelaw and suggested changes in approaches and choices of interventions. In general, an innovation system approach helped to create local confidence, attract attention of government institutions and helped local actors to identify investment areas, develop implementation strategies to increase productivity, define changes as it occurs and minimize conflicts between competing communities. However, the risk of de facto use of a plot of communal land translating into long-term occupation and ownership may be impacting a communal territory and social cohesion that was subject to other collective choice customary rules.

\section{Introduction}

Until the 1970s, pastoralists in the Horn of Africa lived sustainably through a series of institutionalized adaptive strategies where flexibility in time and space for accessing resources (i.e., pasture and water) was crucial (Tsegaye et al., 2013). Pastoralism used to be a successful livelihood strategy, where the rainfall regime is low and unreliable, and where mobility was essential for ensuring access to critical water and feed resources (Gebre-Mariam, 1994; Solomon et al., 2007; Sabyrbekov, 2019). It also provided space for the rangeland to regenerate (Galvin, 2009).

The Afar region, Eastern Ethiopia is characterized by a harsh climate, temperatures reaching up to $40^{\circ} \mathrm{C}$, with highly unpredictable average precipitation between 600 and $5 \mathrm{~mm}$ annually (Rettberg, 2010). The region is dominated by pastoralism (90\%) while the remaining population is practicing agro-pastoralism (Tsegaye et al., 2013; CSA, 2017), with about 1.4 million people depend on mixed stocks of camels, cattle, sheep and goats (CSA, 2017). The traditional livelihood strategy of pastoral communities has been increasingly constrained by decreasing productivity of rangelands to supply the required grazing and watering points (Solomon et al., 2007; Gina, 2015), local conflicts due to competition for these vital resources (Solomon et al., 2007; Gina, 2015), increasing pressure on communal land by foreign agricultural investments and increasingly sealed regional and country borders. From the 1950s, large scale irrigation schemes were implemented in lower Awash of the Afar region that transformed major parts of the pastoral dry season grazing areas into commercial farms, causing a substantial loss of communal pastures and increased conflict for resource among various land users (Gebre-Mariam, 1994; Rettberg 2010). These investments, including the recently developed 
Tendaho sugar estate and expanded irrigation schemes of Tendaho/Kessem-Kabana dams following the Awash river (Rettberg, 2010) are putting pastoralists under extreme pressure. As a result, pastoralists increasingly move with their livestock to the neighboring regions of Amhara, Somali and Oromia in search of feed and water resources, which commonly exposed them to frequent conflicts.

Most importantly, the alternated incidence of recurrent drought and flood had devastating consequences (Bekele et al., 2010; ATPS, 2013). Only in 2017, floods affected about 300,000 people, mainly in the regions of Afar, Gambella and Oromia in Ethiopia (UNICEF, 2017). On the other hand, as recent as 2018, millions of people in Eastern and Southern Africa (for instance, Somalia, Kenya, South Sudan, Ethiopia, Malawi and Zimbabwe) were under extreme risk of food deficit due to drought, including the Afar region. The effect is aggravated by degradation of landscapes and limited capacity of pastoralists to respond to these extreme events (Erkossa et al., 2013).

These extreme weather events, which are expected to get worse due to climate change and variability (Gummadi et al., 2017), led to a renewed debate about the future of pastoralism in the region (Catley et al., 2016). Diversification is becoming necessity for pastoralist societies due to the elevated climate risks, livestock diseases and price volatility for livestock products (Sabyrbekov, 2019). Pathways for pastoral livelihoods in the region, however, are changing, some are moving up into commercialization, others are moving out into activities not linked to pastoralism directly, some are hanging in traditional mobile pastoralism and small-scale agro-pastoralism, while many more are dropping out or exiting into a range of tasks-for-cash and other low-return economic activities (Catley et al., 2016; Lind et al., 2016). However, it is not for granted that pastoralists would diversify their livelihoods with farming successfully. For one, they rarely hold the experience of farming and the basic facilities for farming, including ploughs. Farming in the middle of a pastoral system would also require willingness of other clans to protect crops from the free movement of livestock. Whether it is possible for target communities to negotiate and curb free livestock movement in the middle of rangeland systems is also one of the research questions of this paper.

To support those who opted for small-scale agropastoralism, various authors (Louhaichi et al., 2016; Abdellatif et al., 2017) suggested an investment in the often untapped potential of rainwater management in the drylands. Rainwater management is an integrated strategy that enables drought-prone agricultural systems to systematically capture, store and efficiently use water and nutrient resources on farms, rangelands and watersheds in a sustainable way for pastoral, agricultural and domestic purposes (Amede et al., 2011). Managing runoff at landscape scale brings an accompanied benefit of regulating soil erosion, reducing the risk of gully formation and enhancing ecosystem services. It is becoming urgent for research and development institutions to capacitate pastoral and agropastoral communities employ dryland water management innovations to diversify their livelihoods. This could be partly done by capturing flood emerging from the neighboring highlands and improving soils to enhance production and productivity of pastoral systems, which was another major objective of this paper. Given the fact that the Ethiopian highlands are rarely protected from erosion, the flood emerging from the neighboring highlands carry an annual sediment yields in the ranges between 497 and $6543 \mathrm{t} \mathrm{km}^{-2} \mathrm{yr}^{-1}$, though these vary significantly between different years and sub-catchments (Vanmaercke, et al.,
2010). If well managed, this load enriches soil fertility in the lowlying plains and improves soil water availability, which could be used to produce food and forage crops, in both short and long rainy seasons.

Given the fact that flood irrigation could be abrupt, unpredictable and difficult to regulate (Erkossa et al., 2013), a strategy is sought to maximize its benefit to pastoral systems while reducing its potentially negative consequences on downstream dwellers (van Steenbergen et al., 2011). Flood management is particularly challenging for non-sedentary pastoral communities, as it was the case with communities in Afar, with extensive mobility to neighboring highlands for at least 5 months of the year in search for feed and water during the dry spells. Oweis et al. (2012) identified two differing management of flood-based systems, namely wadi-bed and off-wadi systems, depending on whether the flood is stored or diverted from its natural course to irrigate nearby rangelands.

This paper is presenting a case study whereby an alternative and participatory flood management strategy is sought to increase water access to pastoralists by converting the horrendous flood emerging from the highlands to productive use for rehabilitating degraded rangelands using 'water spreading weirs, WSW' as an entry point. WSW is an old, traditional technology that consists of diverting flash floods from intermittent streams (known as wadis in the Middle East and dongas in parts of Africa) to adjacent tracts of land in small watersheds (Hillel, 2005) for irrigating pasture and crop lands. This system was developed using WSW as the center of innovation (GIZ KfW, 2012). We used the sediment-loaded floods to fertilize and irrigate the lowlands and evaluated agronomic options for growing food and feed crops in the rehabilitated landscapes through participatory and bottom-up processes. The objectives of this paper are to (1) develop flood management systems to rehabilitate degraded rangelands using water spreading weirs as an entry point; (2) assess the performance of food and forage crops under flood-based irrigation farming and pastoral setting and (3) document key technical and institutional innovations for adaptive management of flood-based farming practices.

\section{Methodology}

The research was conducted in the Afar region, Eastern Ethiopia. The Afar Regional State is one of the nine regional states of Ethiopia, with a population of $1,812,002$ (CSA, 2017). We have selected Shekayboru site, Chifra $\left(11^{\circ} 45^{\prime} \mathrm{N} ; 40^{\circ} 57^{\prime} \mathrm{E}\right)$ district and Wokredi site in Yallo district $\left(12^{\circ} 21^{\prime} \mathrm{N} ; 39^{\circ} 52^{\prime} \mathrm{E}\right)$ in Afar for the case study.

\section{General features of Chifra}

Shekayboru in Chifra district was one of the case study sites, which is located in Zone 1 of the Afar regional state of Ethiopia near the base of the eastern escarpment of the Ethiopian highlands (Fig. 1). These are semi-settled pastoralists, with about 26.82 and $32.30 \%$ of total the school aged children are enrolled in school (Gebremedhin et al., 2017), a high level of illiteracy (>85\%) and heavily reliant on food aid for most of the years. The average annual rainfall ranges from 200 to $450 \mathrm{~mm}$, while the average annual temperature is high, ranging from 28 to $40^{\circ} \mathrm{C}$.

The area has two rainy seasons 'Kerma', which is the primary rainy season that historically spanned 4 months from mid-June 


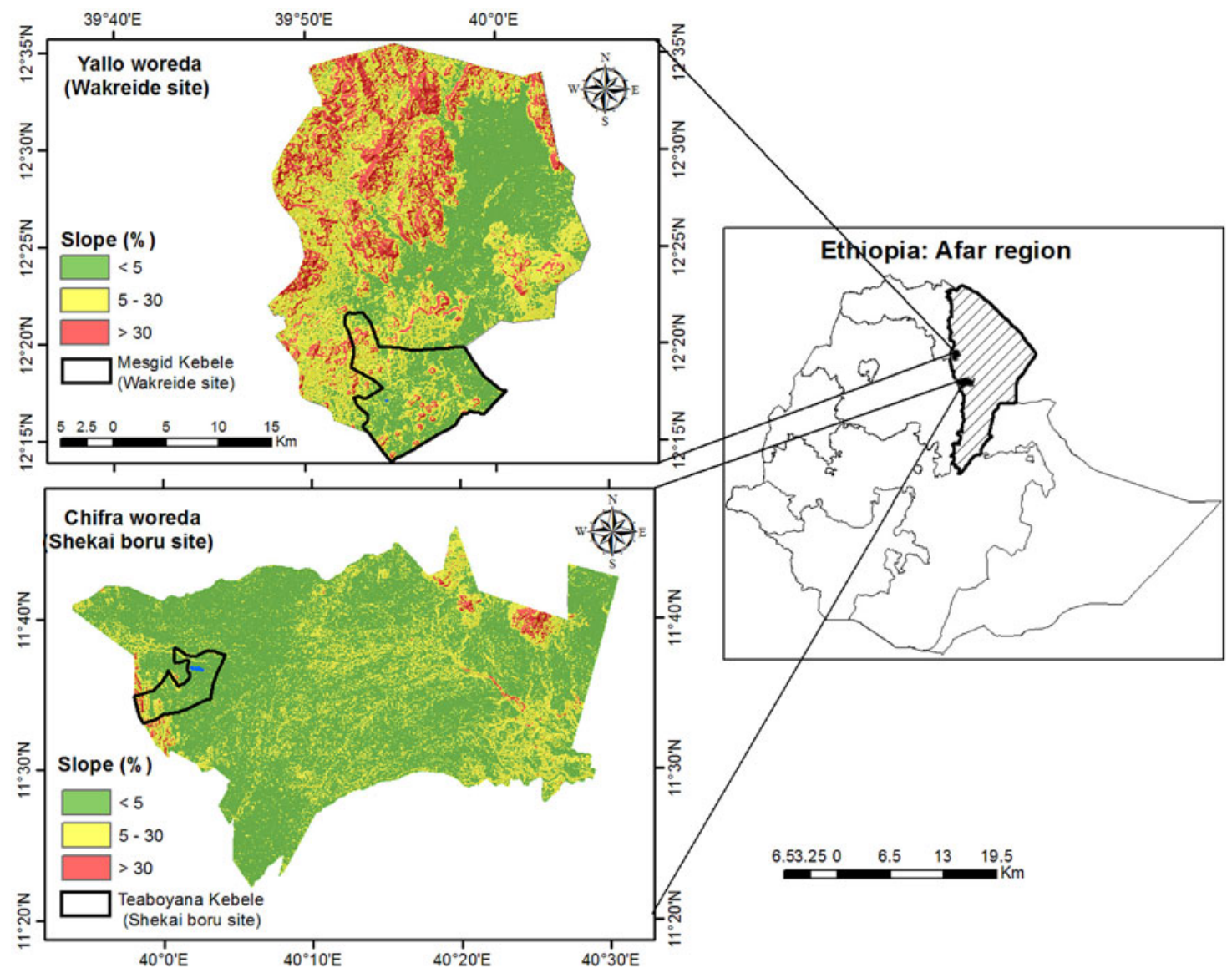

Fig. 1. Location and slope map of Chifra and Yallo districts in Afar showing potential flooding areas in the valley bottoms of the landscape.

through mid-September, is now limited to the month of mid-July and August. 'Dedaa' which historically occurred as occasional rainfall in mid-December and 'Segum' which historically occurred in March and April as a minor rainy season has disappeared entirely. Occurrences of extreme weather patterns like drought and flood are common phenomena of the district.

\section{General features of Yallo}

Yallo district, Wokriede is another case study site, which is located in Zone 2 of Afar (Fig. 1), which is also the drought-prone, livestock-dominated pastoral system. These are predominantly pastoralists, with a high level of illiteracy ( $>75 \%)$, and heavily dependent on food aid for most of the years. The majority of the community migrates with their livestock regularly to faraway grazing areas with milking/weak animals kept around the settlement with limited income-generation activities (Gebremedhin et al., 2017). Unlike Chifra, which is neighboring high rainfall highlands, the floods in Yallo are limited to the nearby chain of mountains receiving seasonal showers. According to key informants, the area was predominantly communal covered by naturally grasses and shrubs, which is being largely replaced by invasive and unpalatable shrub species (Prosopis Juliflora). There was no experience in agriculture (growing of food and feed crops) in the locality before the arrival of this project. It is inaccessible and far away from market opportunities.

\section{Socio-economic survey data collection}

We have conducted district and village level informal baseline surveys and key informant discussions in December 15 to 18, 2015 in Chifra and January 23-26, 2016 in Yallo districts. After researchers comprising of various disciplines including agronomist, livestock experts, socio-economists and extension specialist visited the respective sites and made direct observations of the target study villages, we have collected the baseline data through focus group discussions, semi-structured interview and key informants. A pre-tested, semi-structured questionnaire was used to collect baseline and mid-project data through face to face interview of about 49 households in Shekayboru and 35 in Wokriedi, administered to the targeted shakayboru and Wokriedi pastoral villages. In each village, focus group discussions comprising of 15-20 participants were also held in the presence of the head of the pastoral and agropastoral district bureau head and prominent clan leaders in order to cross check and complement the information collected through individual interview and to elicit data from communal perspectives. The group discussion was used to identify community challenges in terms of resources availability, drought, flood, food security, mobility, conflicts etc. but also in identifying local institutions that are prevailing within the pastoral communities to manage these challenges.

We have also conducted a mid-project impact survey in February 18 to 22, 2019 in both locations to assess the outcomes and impacts of the project from the perspective of (agro)pastoralists and institution leaders (Table 1). Besides the communities, we 
Table 1. Summary of impact assessment interventions in Shekayboru, Chifra and Wokriedi, Yallo districts in Afar region, Ethiopia

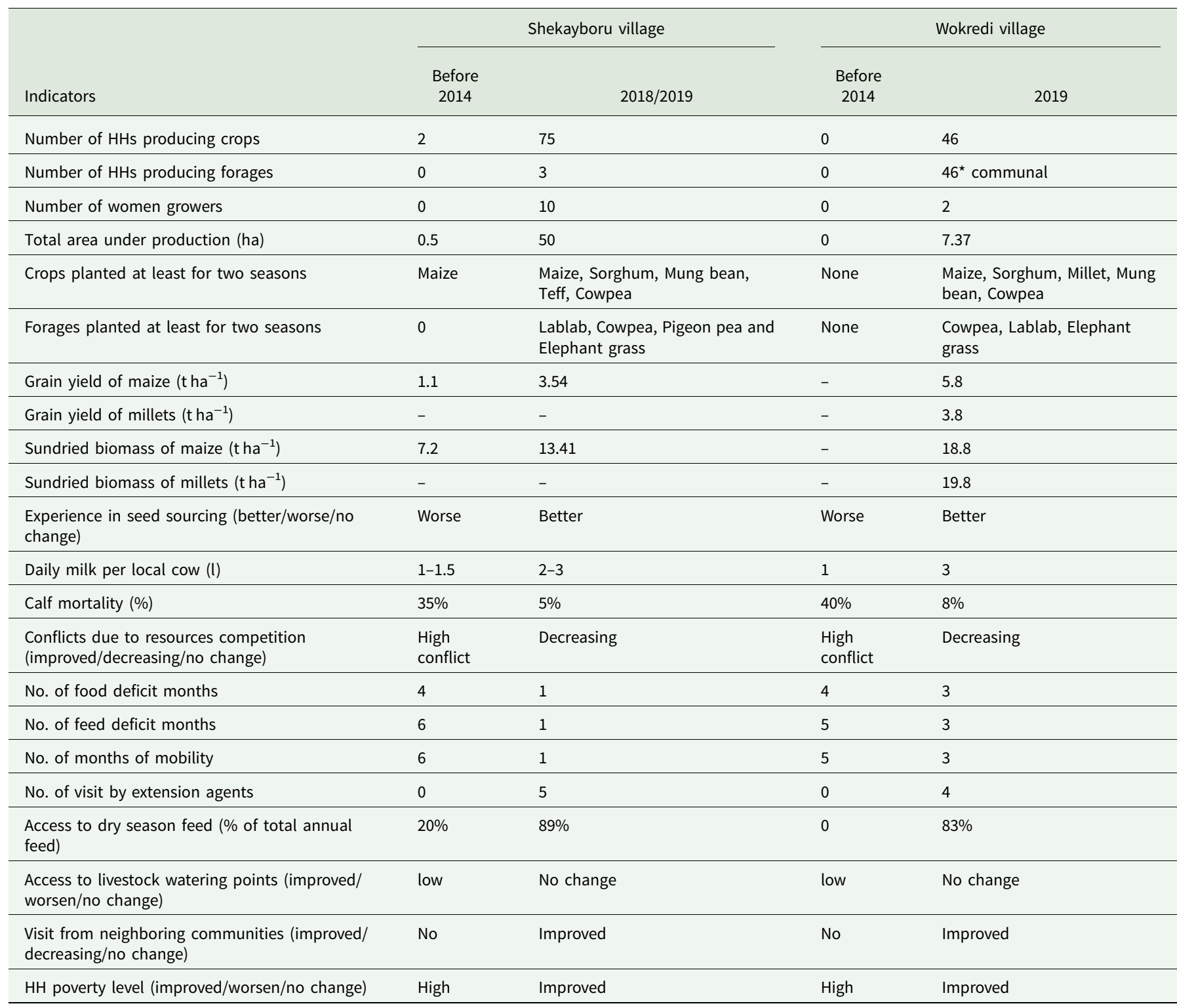

have also collected information from government institution at different levels, including district heads of the Pastoral and Agropastoral Development offices (PADO). The survey focused on the most interesting changes that communities may have observed, namely (i) change in crop and forage production and productivity, (ii) change in institutional services, (iii) change in their knowledge and behavior and (iv) change in risk management and resilience.

\section{Agronomic management}

By being predominantly pastoralists, the two target kebeles had very limited experience in farming and hence the researchers have introduced not only seeds but also agronomic practices. Improved crop and fodder varieties, with early maturity and adaptable to dry climates were selected. Maize (variety Melkassa 2 and 4, 110 days of maturity), Sorghum (variety Melkam and Girana, about 130 days of maturity), Mung beans (variety N-26) and Napier grass, Lablab (variety Acc147) were planted between July 20 and 28 in the years of 2015, 2016 and 2017 using local labor in rows. The planting time followed the arrival of flash floods. We have followed recommended seed rates, except for Maize. We have increased the seed rate of Maize to $45 \mathrm{~kg} \mathrm{ha}^{-1}$ to increase stover yield and minimize the risk of an early offset of floods. The alluvial nature of the soil did not require multiple ploughs, ploughing was done only during planting using a pair of oxen. We did not apply any chemical fertilizer, rather fully relied on the alluvial soils of the location. There was also a very limited weed in the farms, which was removed manually. Harvesting and thrashing were also done manually. We took samples from $4 \mathrm{~m}^{2}$ area in three representative locations of each farm, dried samples of both grain and biomass up to constant weight and estimated yield based on the land area.

\section{Innovation for flood-based adaptive management}

Innovation is a non-traditional path of making things happen better or differently, often by dramatic changes rather than incremental gains (Perrin, 2002), which would require substantive 
behavioral and institutional changes. It is imperative to note that the pastoral systems, which relied their livelihood based on mobility and conflict resolution, required a substantial behavioral change to adopt improved alternative livelihood systems. Adopting new innovation is also not linear, but based on what Raymond (2001) refers to as a 'complex adaptive system' (CAS), which demands adjustments and timely interventions. In a CAS, 'agents' (i.e., someone with agency-the capacity to change something) use strategies in their interactions with other agents and with artefacts (Amede et al., 2009). The major 'agents' in this engagement were community leaders, so called 'Kedoh Abbobati who were keenly analyzing the potential benefits and drawbacks of the WSW-based innovations and suggested changes in approaches and choices of interventions considering the local socio-cultural settings. This joint engagement with the community leaders and local institutions led to participatory decision making in selecting what works, copying, recombining and inventing constantly introduces novelty.

Designing dryland management innovation systems for facilitating farming system change could help local actors to develop implementation strategies to promote sustainable systems, to define changes as it occurs, to describe the links between system components and to identify indicators to measure both processes and impact of innovations (Springer-Heinze et al., 2003; Amede et al., 2009). Recognition of local adaptation is seen as an entry point to strengthen the resilience of local people to extreme shocks (ATPS, 2013). We have adapted an innovation framework (Amede et al., 2009) for facilitating local adaptation of interventions at community and district scales, which comprised three key innovation components, namely the policy, institutional drivers and technical drivers (Fig. 2). These are typically scaledhence, policy is often broad-scale, institutions at an intermediate scale and technological innovations 'nested' or 'embedded' within these contexts. The integration of these various innovations is envisaged to positively affect landscape restoration and improve pastoral benefits in terms of increased income, food and resilience.

\section{Technical innovations for adaptive management of flood-based land restoration}

\section{Construction of contour-based water spreading weirs}

In Chifra, Shekayboru, five cascaded weirs (Fig. 3) were built with an average distance of 50 to $180 \mathrm{~m}$ from each other, depending on contour, flood intensity and sediment load. The weirs were built in the foot slopes of Tehuledere mountainous of the Amhara region in 2014 and 2015 to regulate seasonal floodwaters, reduce runoff and minimize erosion. Similarly, three successive weirs were built in Yallo, Wokriede in 2016 and 2017, while agricultural operation started in the main season of 2018. In Wokriede, excessive runoff was collected from drought-prone nearby local hills as it does not neighbor with highlands. The weirs are made of natural stones and cement and consist of a spillway in the dry riverbed itself lateral abutments for stabilization and wing walls that span the width of the valley. It has evolved from the traditional Nabataan system in the Negev deserts and intermittently used in the Sahel (Hillel, undated). Given the high rainfall $(950 \mathrm{~mm}$ per annum) of Tehuldere hillslopes and shallow soils, it produces seasonal high intensity flood flashes. We have collected this run-off from a large area of these watersheds and directed it to a relatively small cultivated area in the bottomlands. The weir ensures that soil moisture is increased, and soil loss arrested while it makes provision for excess water to drain (GIZ KfW, 2012; Schöning et al., 2012). It was found to be effective to spread flood out of the concentrated flow into the plain so as to reduce the velocity and distribute flood to the wider plains (Hillel, 2005). Technical details of successive low retention walls, WSW is presented elsewhere (Hillel, 2005; GIZ KfW, 2012).

\section{GIS-based farm level land suitability map}

The flow path and intensity of water spreading in the plain (above and below the weir) is controlled by the in-situ microrelief, slope, height difference between the valley and plain surface and flood volume. These landscape characteristics have contributed to a varied moisture regime, flow direction and intensity above and below the structures, which created huge soil moisture variability as well as variable land uses (GIZ KfW, 2012; Schöning et al., 2012). The soil moisture regime was recurrently measured using a soil moisture sensor (TDR-300; Spectrum technologies) at a soil depth of $0-20 \mathrm{~cm}$ and 21 to $40 \mathrm{~cm}$ in multiple directions from the weirs. The inverse distance weight geospatial conversion tool was employed to generate a raster gravimetric soil moisture maps. The results demonstrate huge moisture variability with differential spatial and temporal patterns due to the introduction of weirs, suggesting differing strategic use and crop allocations. We tracked the entire field using GPS (Fig. 4) in order to locate plots with similar soil moisture regimes and soil nutrient levels, which was used to classify the landscape into different land use maps. We also tracked crop performance on every piece of land from previous years for suggesting crop or forage suitability analysis. From the overall physical assessments of these structures, four land quality zones were proposed for allocating crops and management options as described as follows. These GIS-based solution guide (Fig. 4) was designed to guide extension workers and farmers to target their farm plots with differing management options.

\section{Choice of appropriate crop types and varieties}

Given the fact that pastoral communities rarely practice farming, there were very limited germplasm choices in the system. In 2016, we grew local varieties of maize and sorghum, which have completely failed due to short flooding seasons. In 2017, we introduced high biomass producing but early maturing, drought resistant varieties of Maize (Melkassa-4 and Melkassa 2) and Sorghum (Girana) along with drought resistance legumes, mainly mung bean and pigeon pea and drought resistant forage grasses. We have increased the plant population of crops (e.g., Maize, 80,000 plants) to increase stover yield and guarantee production of feed, even under scenarios of terminal drought. The choice of appropriate varieties followed the GIS-based maps (Fig. 4). Using expert knowledge, plots with high moisture content were allocated for maize and sorghum while plots with low moisture content were allocated for early maturing legumes or grasses. We have been working with the PADO of Chifra and Yallo to develop community-based seed systems by providing startup seeds of improved varieties and training subject matter specialists of these bureaus for sustainable input delivery.

\section{Institutional innovations for adaptive management}

A system shifts from pastoral to agropastoral farming demands considerable transformation in terms of institutional arrangements and behavioral change (German, et al., 2017). As described by Wilson (1982) in other settings, local institutions called 'Kedoh 
Fig. 2. Components of innovation systems to address poverty, environmental degradation and resilience through improved flood-based land restoration interventions (modified from Amede et al., 2009).

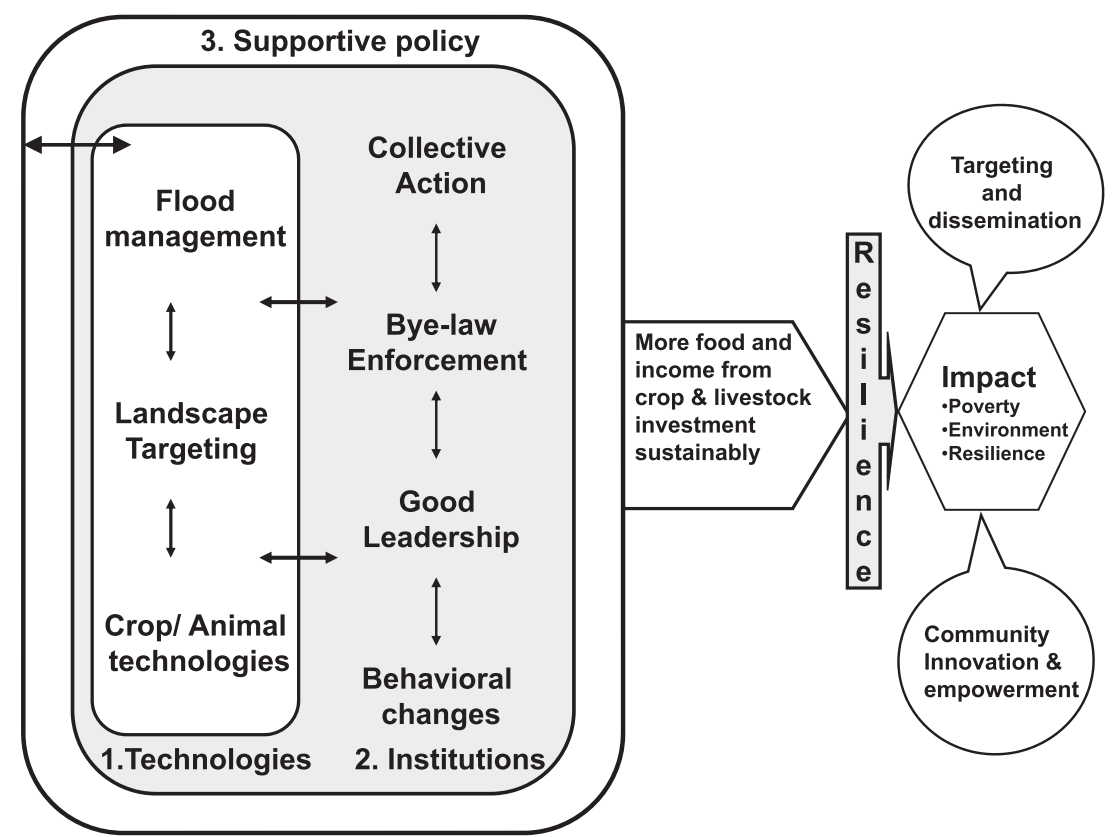

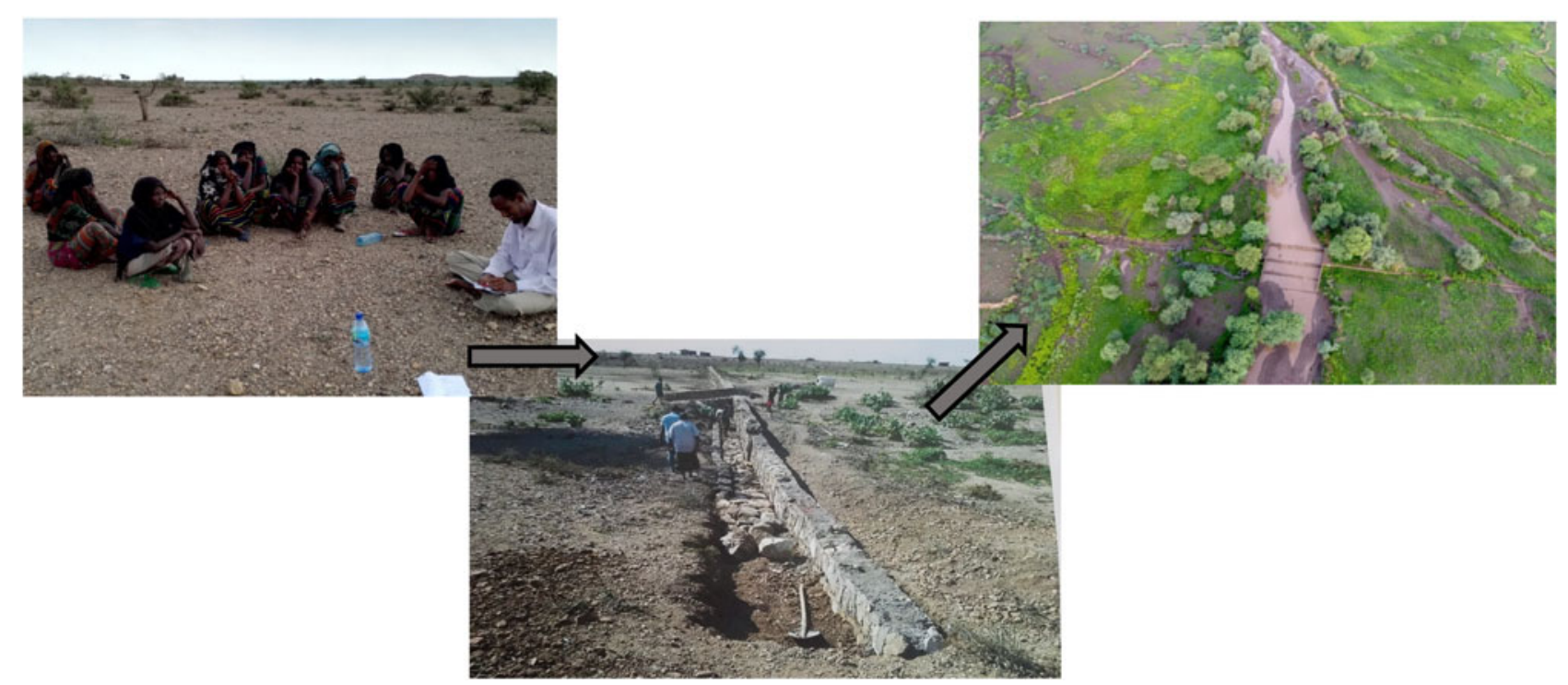

Fig. 3. Water spreading weirs constructed in the degraded landscapes of Shekay boru, Afar, Ethiopia, and the land cover changes due to the interventions (photo credit: GIZ).

Abbobati' in Afar embraced the intervention due to potentially three basic circumstances, namely:

(1) that drought and flood were two major livelihood predicaments encountered by the community repeatedly under more or less similar circumstances in which individualistic opportunistic behavior is seen to destroy the possibilities for collective gain;

(2) an information network-arising mainly from external players (e.g., ICRISAT and GIZ) along with the increasing local demand created an opportunity, which can form the basis for identifying and negotiating possible social rules and

(3) there exists own, traditional pastoralists-oriented collective basis for the enforcement of these rules

\section{Development and enforcement of byelaw}

In Afar, traditional institution called 'Medaa $A b a$ ' is a social system that governs the proper management and fair utilization of natural resources. It is a hierarchical structure starting with clan leaders at the top level and reaching down to the head of a household (ATPS, 2013). After multiple awareness creation meetings with Medaa leaders in their respective villages about the potential benefit of the weir-based innovations in terms of improved access to livestock feed, increased productivity of dryland crops and decreasing risk of flooding the leaders have called the community for consultation and creating collective action. However, the decision on such major landscape scale intervention was beyond the community and demanded the consent and leadership of the higher-level local leaders, Kedoh Abbobati. One primary question 


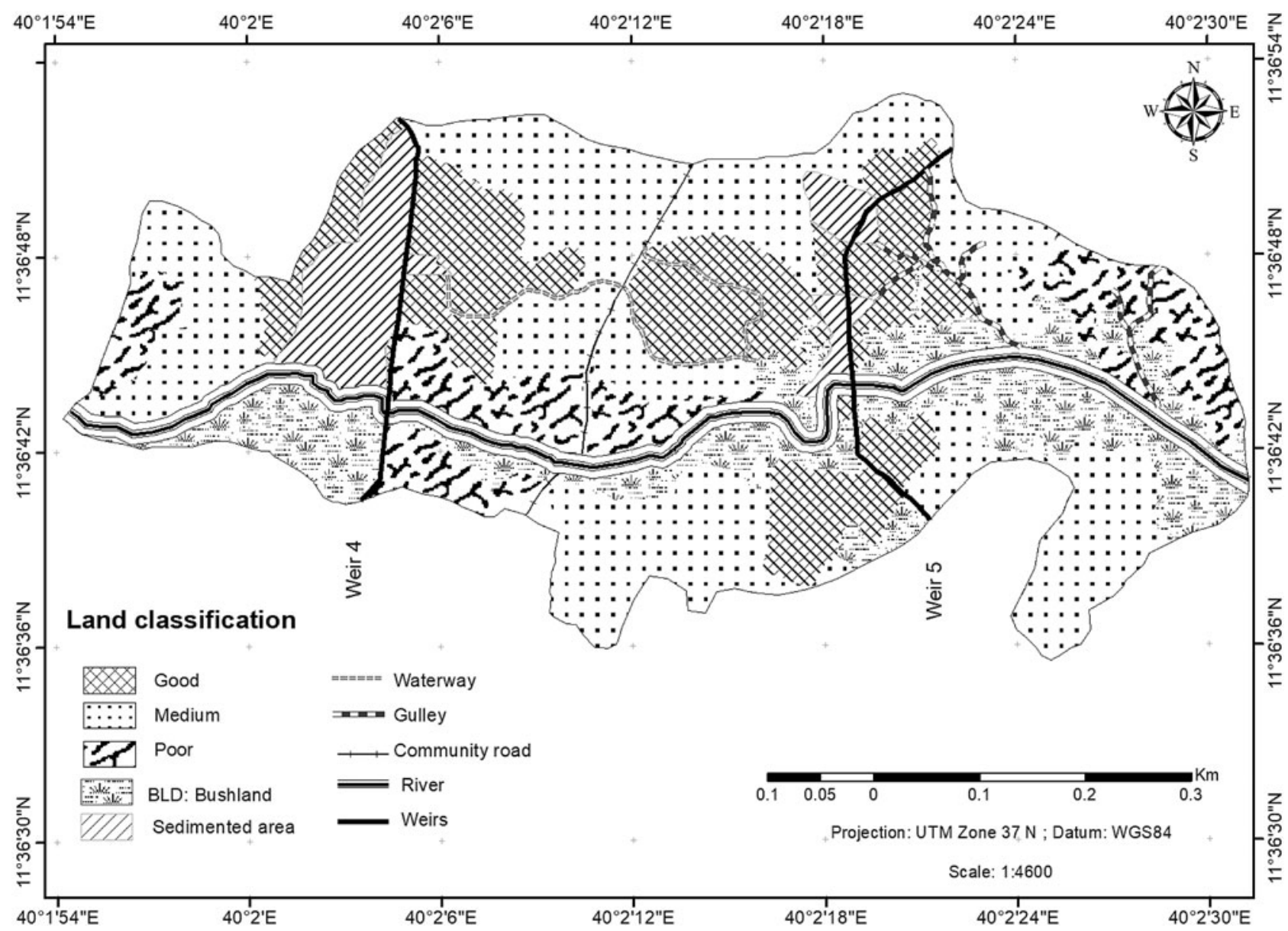

Fig. 4. Land use suitability maps using soil moisture regime and previous crop performance as proxy indicators in Shekayboru, Chifra, 2017.

was on how to minimize free movement of livestock in a pastoral setting and also how to manage crop and forage production in communal setting. After the blessing by Kedoh Abbobti, and discussion with key informants, the community members agreed to jointly drafting and facilitating broad range by-laws capitalizing on the perceptions and experiences of some members the pastoral community, who have witnessed farming while migrating with their livestock to the highland systems. After the pastoral communities debated, formulated and endorsed the byelaws, the local leaders briefed PADO to enforce the penalties emplaced by the community as agreed by the pastoral communities themselves. Accordingly, rehabilitated landscapes and farm lands were to be protected and any violation of the rules of natural resource use (such as cutting of trees and animal trespassing into the farm areas) was reported to the traditional judge/arbitrator by the leader of the Feema-abba to impose punishment and fines on the perpetrators. The byelaw also stipulated that the owner of the farm should fence his farm appropriately, particularly during the non-growing periods. If fenced crop and fodder is damage by animals, the owner of the animal would be fined 100, 200 and 300 birr, which was equivalent to $3.3,3.6$ and 10 USD per animal in the first, second and third incidences, respectively. If the owner failed to keep his animals away, she/he will be referred to PADO for stronger action. Moreover, PADO was engaged not only as law-enforcement institution but also as a mediator among the different clans. These rules were enforced so strongly by the Kedoh
Abbobati that despite the huge livestock number in these agropastoral communities, crop damage by the roaming livestock was negligible. There were only about eight cases of penalty reported in 1 year.

\section{Capacity building}

Given the fact that these communities were predominantly pastoralists, they had limited experience in farming. This was initially noted as a major bottleneck to flood based farming, which could have halted farmer innovation and learning. Though too often 'capacity building' helps us to do what we already do, only better, the path forward remains largely the same (Harwood, 2014). This engagement with pastoralists called for change but not incremental modification of the existing system. By organizing various capacity building events for willing pastoralists in agronomy and farm operation, both in classrooms and in the field, we were able to facilitate change in attitude, which quickly created increased demand for farm inputs and extension services. Starting with eight lead households in the short rains of 2016, whereby we demonstrated the farming potential of the landscape in Shekayboru, it attracted about 52 household in the following year, and there was an increasing demand since then. However, dynamics of pastoralist sedentarization may also imply a competitive rush to access land for fear they would be completely excluded from the rangelands they once used, rather than the desire to farming (German et al., 2017). 


\section{Policy influence in favor of flood-based land restoration}

\section{Regional level influence}

The most important impacts that this initiative has brought about is the considerable interest and impact in changing attitudes of regional and federal government officials. It provided evidence on best-bet flood management approaches to policy makers, which enhanced linkages among stakeholders and more collaborative working environments. Three Ministers of the federal government has visited the site in 2017 and interacted with the community and local actors on how to take the best-bet interventions to wider scales. Governmental and non-governmental institutions were also able to get feedback on the required investments and policies to support livelihoods of pastoral systems. Above all, the innovation framework (Fig. 2) has enabled researchers, extension personnel, development workers and policy makers to understand, appreciate and embark on the need for knowledgebased and participatory landscape restoration approaches. There is already a high level demand to identify additional potential flood-based bright spots across the country for suitability analysis and further investment.

\section{Local level influence}

The major engagement of the PADO in the districts was to solicit food aid and livestock feed during drought periods. The shift in developmental work was new, PADO officials played a crucial role in mobilizing the community, guided the partnership on local needs and priorities and inspected the progress made through formal and informal meetings. Although traditional rules and norms are more potent than the less-enforced policies in Ethiopia (Alemayehu, 2013) the institutional endorsement of PADO was instrumental to create collective action among the pastoralists for the successful implementation of project components.

\section{Effects of flood management interventions}

\section{Changing land quality due to floods}

The flood emerging from the Amhara highlands commonly carry significant load of soil and sediment to downstream sinks (Erkossa et al., 2013). Flood variability over 4 years study in Afar showed that about 1.2 million and half a million hectares of land received flood during long and short seasons of the year on regular basis, respectively (Murali et al., 2019, this volume). The sediment-laden flood created differing land quality within the WSW treated landscapes (Fig. 4) though the effect largely depends on the flood amount, composition and intensity. The different land parcels, which had significantly different crop performances and yields were grouped into at least four crop management zones depending on the soil water holding capacity, soil texture and crop performance (Fig. 4). In general, many pastoral areas contain small, highly productive areas which make a disproportionately large contribution to the area's total forage production (Vetter, 2005), which needs to be mapped and managed for sustainable use.

\section{Productivity outcomes}

Our selected intervention sites used to be considered as nonsuitable for crop production until our group has initiated this project. The year 2016 was a relatively dry year in the neighboring highlands (about $600 \mathrm{~mm}$ of rain per annum) and flood coming from the highlands was limited both in amount and frequency (not more than four floods) (Murali et al., 2019, this volume). In Chifra, the communities managed to produce about 280 tonnes of biomass in a season from 35 ha of land, from what used to be a barren land (Fig. 3). Maize was planted on $28 \%$ of the area mainly in the good and medium suitable management zones (Fig. 4). By increasing the plant population of Maize to 80,000 plants per hectare, the biomass yield was reaching up to 15 tonnes per ha (Fig. 5; Tables 1 and 2), which is significantly higher than the yield level of small scale farmers in the highlands. The sorghum crop (Girana 1, 130 maturity days) has also produced biomass up to 3.5 tonnes per ha though it did not manage to set seed due to the extended growth periods. The highest fitting crops to the system were dryland legumes, particularly mung beans, cowpea and pigeon pea. Mung bean is one of the most demanded export crops in the country with amazingly high grain yield in these landscapes.

On the other hand, 2017, 2018 and 2019 were very good years in the highlands, releasing flood to our sites for about 70 days (Murali et al., 2019, this volume). In Shekayboru, we covered about 47 ha of land with crop and forage interventions, namely maize, mung beans, lablab, cowpea, sorghum and teff, with various land allocations (Table 2). The remaining area was left for rehabilitating natural grazing area. The average grain and forage yield of crops was beyond our expectation (Table 2; Fig. 5). In 2017, the landscape produced about 583 tonnes of livestock feed (Fig. 5), which is about 11.2 tonnes of biomass per hectare.

After realizing the productivity benefits from flood management interventions (Table 1, Fig. 3), the demand for land has significantly increased. Although there could be economic costs due to the encroachment to the rangelands, the biomass production of the rehabilitated farms was about $3 \times$ to the neighboring rangelands (Getnet et al., 2019, this issue). There has also been an increasing seed demand following these interventions.

\section{Environmental outcomes}

Rangeland degradation implies a lower biological diversity, loss of top-soil, change in simple composition and flora and loss of productivity (Gina, 2015; Abdellatif et al., 2017) which was the case in our pilot sites. These low-lying landscapes used to be also affected by torrential floods, washing away crops, rangelands, tukuls and other assets recurrently. The WSW-based intervention changed the flow path and intensity of water spreading in the plain (above and below the WSW structures), which was altered by the in-situ micro cliffs, slope range where the water gets energy, height difference between the valley and plain surface, and flood volume. The landscape characteristics have been drastically changed (Fig. 3), enhanced soil moisture and reduced flow intensity thereby minimized erosion effects (Erkossa et al., 2013). For example in Shekayboru, extended and deep gullies, which used to separate communities and limited livestock movement were filled within two seasons thanks to the sediment load emerging from upstream locations. We are expecting fast recover of the ground water at a scale. Forecasting short-term and nearterm dynamics of resource flows (e.g., flood) would present a chance for resource managers to develop strategies that make the most of opportunities during favorable periods and avoid adverse outcomes under unfavorable situations (Bradford et al., 2018). 

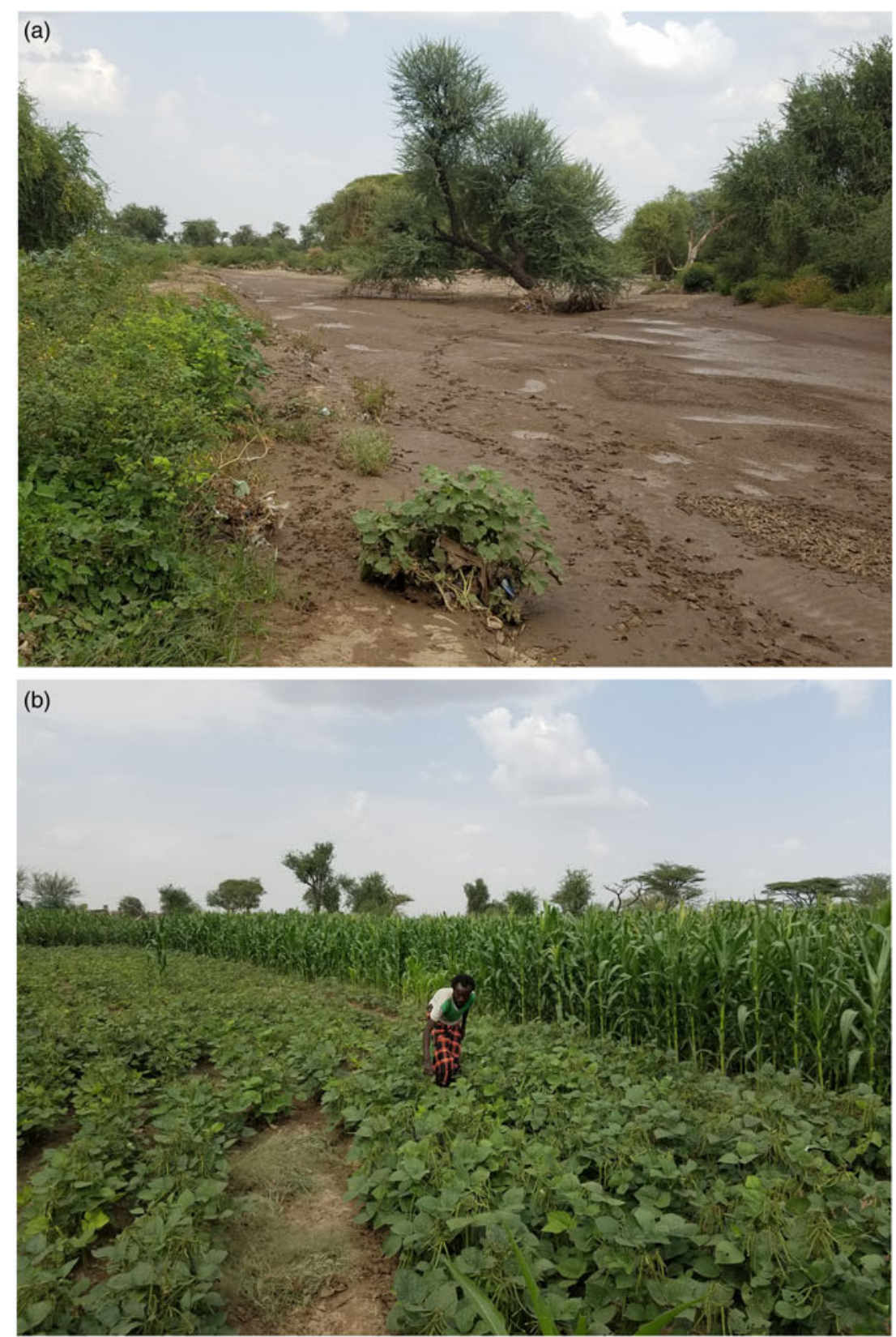

(c)

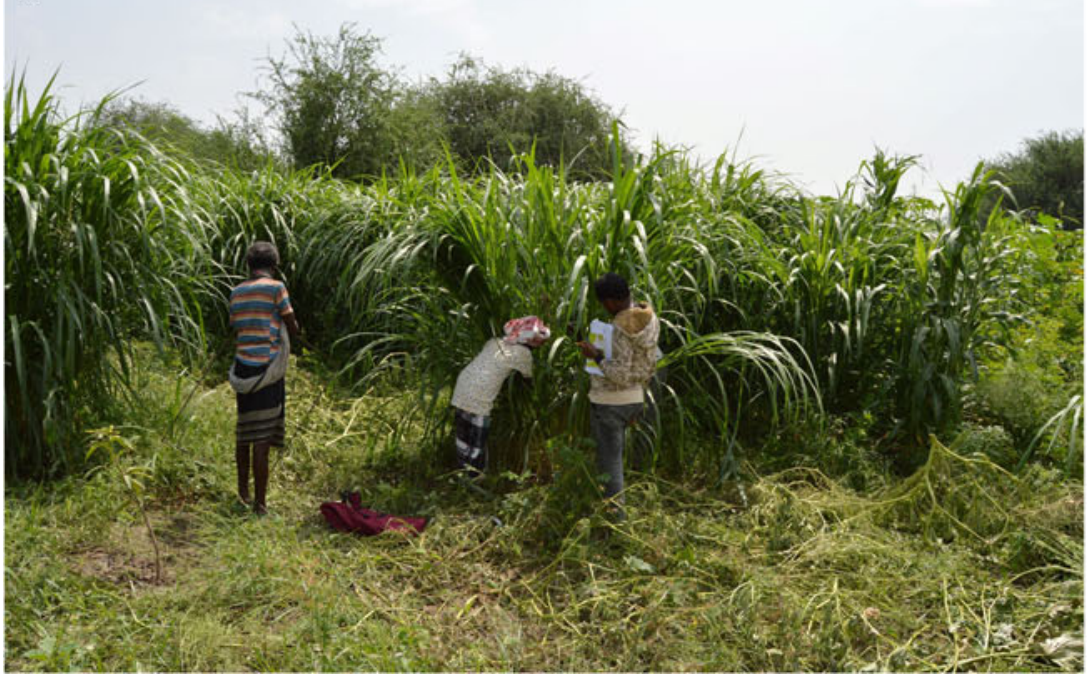

Fig. 5. Rehabilitated gully (a), crop performance (b) and Napier grass performance (c) grown in fertile zones of the rehabilitated landscapes, following suitability maps as indicated in Figure 4. 
Table 2. Crop type, biomass and grain yield of crops produced with WSW-based interventions in Chifra and Yallo districts, 2017

\begin{tabular}{|c|c|c|c|c|c|c|}
\hline Crop type & Area covered (ha) & \multicolumn{2}{|c|}{ Shekayboru, Chifra } & \multicolumn{3}{|c|}{ Wokriede, Yallo } \\
\hline Maize & 26.55 & 16.13 & 5.53 & 0.23 & 2.48 & 2.36 \\
\hline Sorghum & 1.222 & 3.39 & 0.62 & 0.07 & 1.43 & 1.25 \\
\hline Cowpea & 8.13 & 3.48 & 1.34 & 0.03 & 0.60 & 0.37 \\
\hline Elephant grass & 0.30 & 12.00 & - & - & - & - \\
\hline Pigeon pea & 0.75 & 14.0 & - & - & - & - \\
\hline Lablab & 4.335 & 8.0 & - & 0.05 & 1.43 & 0.7 \\
\hline
\end{tabular}

NA, not applicable.

As this landscape was an abandoned land, there is no control for comparison.

\section{Social outcomes}

Despite being very close to the district town of Chifra, about $10 \mathrm{~km}$, the communities rarely received social services. For one, being agropastoral communities, with frequent mobility, the local government did not attempt to build schools or health posts in the area. The WSW-based landscape development became an incentive for the communities to gradually settle, which attracted investment in terms of the construction of elementary schools and health post. Their local leaders were recognized by the local administration and were participating in critical decision making. The number pastoralists choosing a sedentary way of life is increasingly significantly because of recurrent droughts, conflicts, rangeland degradation, declining productivity and accelerating population growth (Bekele et al., 2010; Lind et al., 2016). While the men from Afar were still migrating with their livestock, women took the responsibility of farming, which gave them an enormous recognition by their husbands and the local communities. The intervention has changed the social relationship and gender balances. For instance, out of the 121 household engaged in this watershed about $10 \%$ were female (Table 1), which is unprecedent in a men dominated pastoral cultural setting. However, there is a need to assess the added labor burden on women and men pastoralists.

Community members divided the communal land among the clan members, organized themselves to enforce local rules that would govern land allocation principles and started to invest money and labor for improving the productivity of the newly developed systems. One major investment was collective fensing of an area of 50 ha of rehabilitated land to protect from livestock. The community engagement also included maintenance of structures, opening up new waterways, negotiating with neighboring communities to curb livestock movement during the growing seasons and developing a labor support arrangement to support women and the elderly. The customary rules were effectively used to negotiate with other clans and curb possible grazing damage.

The land distribution also became an incentive for the development of new by-laws that would protect the property of individual households. One outcome out of this engagement was limiting the free movement of livestock of their own but also those from nearby town and neighboring communities, which used to put huge pressure on the resources of the respective villages. Moreover, by being the only source of dry season feed in the area, these communities were highly recognized by the local communities for their support in availing feed for others, particularly for calves and milking cows. However, the long term implication of this investment on future social cohesion and equitable use of the various clans and social groups must be further studied.

\section{Discussion}

Various scholars showed that changes in land use and management could lead to negative consequences affecting the local populations, landscape functionality and ecosystem services (Statuto et al., 2016). When attempting to facilitate landscape change towards positive outcomes, several issues should be taken into consideration (German et al., 2007): (a) the level at which planning is carried out, (b) whether to plan for multiple issues (e.g., drought or flood management) simultaneously or around specific issues (e.g., farm productivity) and (c) how to address social trade-offs in decision-making. Our results showed that there is a high scope to restore the productivity of degraded landscapes in SSA, including the pastoral systems, through participatory planning, adaptive management and responsive partnerships. Adaptive management need sustained support to test and refine feasible strategies (e.g., WSW-based landscape management) to understand complex systems and exploit management opportunities using short and near term climate forecasts (Hardegree et al., 2017) and expert based assessment tools. These principles are used in many science-management partnerships to explore solutions to natural resource management challenges (Bradford et al., 2018). However, change requires intensive engagement in pastoral systems, who face a host of trade-offs in shifting from collective to individualized use of rangeland (Gebre-Mariam, 1994; Karl, et al., 2012) and to try out new farming methods and practices at the outset. Initially, there was a strong resistance by Kedoh Abbobati with the fear that the introduction of the structures would bring about unintended consequences, including local conflicts due to competition for resources. This local resistance softened, once they witnessed the very high potential and positive landscape changes, particularly the amount of feed and fodder generated at plot, farm and landscape levels. The high yielding forages tested by two risktaking pastoralists served as an entry point to motivate more community members to try out new interventions. Early success at the 
farm level helped to move the discussion to more complex livelihoods' agenda, particularly through the support of trusted institution, e.g., PADO.

\section{Complementarities and contradictions between individual and collective interests}

The fast-changing landscape attracted new actors. The powerful elite, partly educated, clan members residing in nearby towns started to claim ownership of the fertile patches of the landscape while the pastoralists preferred for 'wait and see' approaches. German et al. (2017) also indicated that those pushing for individualized landholdings were found to be those spending considerable time outside their communities due to education, military service or employment as civil servants. These experiences had inculcated in their ideologies of modernization, while giving them greater access to the land as well as to economic resources that could be used to increase returns from land (Lesorogol, 2008). When the residing 'late comers' realized that they lost the relatively fertile patches, they requested GIZ-SDR to build an additional weir upstream to capture the sediment and rehabilitate a new patch of the communal land. However, the additional weirs have brought the new comers in tension with downstream farm 'owners' due to flood reduction at the onset of upstream rains. The risk of not having a broader collective agreement on how the land would ultimately be allocated would still be controversial as de facto use of a plot of land translates very easily into long-term occupation and ownership-impacting a communal territory that was subject to other collective choice rules (German, personal communication, 2019). However, there were also complementarities between individual and collective processes. These included new ways of introducing byelaws, collective removal of sediments from selected spots, establishing social organization to derive greater benefits from food and fodder farming, but also accessing better fodder market opportunities through economies of scale and collective lobbying for new schooling and other social benefits. The strict use of drought alleviating strategies used to be enforced by customary institutions, however, these structures have weakened over time, with more and more people turning to the official political-administrative structures, in our case the PADO, for guidance and enforcement of land use (Lind et al., 2016).

While it is as yet unclear how the new change in production systems would affect resource access among the pastoralists, it may result in decreased collective use or outright exclusion of members of other clans that used to graze the area. Changes in Ethiopian federal government policy presented new challenges, limiting movement of pastoralists to well-endowed areas (Lind et al., 2016), which would add pressure to newly rehabilitated landscapes, like that of Shekayboru and Wokredi. This raises additional challenges for inter-ethnic parity, which can lead to inter-ethnic tension, if their pursuit of farming is seen as a threat to the other pastoralist groups using the area (Gebre-Mariam, 1994). The plausible scenario could be for the other clans to demand similar investments and expand the sphere of rangeland rehabilitation and expansion.

\section{Conclusion}

As this study has demonstrated, adoption of flood-based farming could be an important strategy to diversify livelihoods and rehabilitate degraded rangelands of pastoralists in a very short period of time. In some cases, converting rangelands to farmlands reported to cause rangeland degradation and biodiversity loss (Louhaichi et al., 2016). Our findings demonstrate that restoration of an abandoned bare land through flood conservation measures and appropriate food and feed crops could bring about a significant contribution to livestock-based livelihoods. By employing adaptive management, sustaining support to test and refine feasible strategies (e.g., WSW-based landscape management) to understand complex systems and exploit management opportunities using various agronomic and management tools there is a huge chance to improve the livelihoods of pastoralists in East Africa. However, there is a need for joint planning and participatory engagement, involving clan leaders 'Medaa Aba' and Kedoh Abbobati. Murali et al., 2019 (this volume) have identified potential areas where these WSW-based interventions could be scaled-up in the whole of Afar, in close collaboration with the local authorities and the communities. However, for this innovation to be widely adopted and sustainably used, there is a need for additional research in the area land allocation, property rights, rights of inheritance and consequences of changing from pastoralism to agro-pastoralism for the livelihoods and the policy framework associated with pastoralism.

Acknowledgement. This research was supported by BMZ-Germany, through GIZ-SDR Ethiopia and the CGIAR Research Program Water, Land and Ecosystems (WLE) which are carried out with support from the CGIAR Trust Fund and through bilateral funding agreements. We thank the communities and local authorities, particularly the Pastoral Agricultural Development Office (PADO) of Chifra and Yallo districts for facilitating our engagement. We also acknowledge the strong technical support from Dr Mezgebu Getnet, Tadesse Gashaw, Dr Mohammed Abate, Abubeker Mohammed, Mohammed Abdulatife, and local support of Indris Siraje and Henok Aragie.

\section{References}

Abdellatif BM, Neffati M and Belgacem AO (2017) Restoration and rehabilitation of degraded Saharan communal rangelands in southern Tunisia. Journal of New Sciences 25, 6.

Alemayehu T (2013) Spate irrigation in Ethiopia: potential, development status and challenges. In Erkossa et al. Flood-based farming for food security and adaptation to climate change in Ethiopia: potential and challenges. Proceedings of a workshop, Oct 30-31, 2013. Adama, Ethiopia. International water Management Institute (IWMI). pp. 23-39.

Amede T, Geheb K and Douthwaite B (2009) Enabling the uptake of livestock -water productivity interventions in the crop-livestock systems of sub-Saharan Africa. The Rangeland Journal 31, 223-230.

Amede T, Tarawali S and Peden D (2011) Improving water productivity in crop-livestock systems of drought-prone regions. Editorial Comment. Experimental Agriculture 47, 1-6.

ATPS (African Technology Policy Studies Network) (2013) The rationale and capacity of pastoral community innovative adaptation to climate change in Ethiopia, ATPS Research Paper No. 25. Available at file://C:/ Users/Administrator/Downloads/rps25.pdf.

Bekele G, Demeke F and Zahra Ali Z (2010) Livelihood-Based Drought Response in Afar. Impact assessment report. Addis Ababa. 25 pages. Available at https:// ethiopia.savethechildren.net/sites/ethiopia.savethechildren.net/files/library/ Final\%20report\%20of\%20Afar\%20Respons-Final\%20report\%20of\%20CARE \%20SC\%20UK\%20and\%20FARM\%20PIA.pdf.

Bradford BJ, Betancourt LJ, Butterfield JB, Munson MS and Wood ET (2018) Anticipatory natural resource science and management for a changing future. Frontiers in Ecology and the Environment 16, 295-303.

Catley A, Lind J and Scoones I (2016) The futures of pastoralism in the Horn of Africa: pathways of growth and change. Revue scientifique et technique Office international des épizooties 35, 389-403.

CSA (2017) Population projection of Ethiopia for all regions at woreda level from 2014 to 2017. Federal Democratic Republic of Ethiopia Central Statistical Agency. Retrieved 11 October, 2019. 
Erkossa T, Hagos F and Lefore N (2013) Flood-based farming for food security and adaptation to climate change in Ethiopia: potential and challenges. Proceedings of a Workshop, Oct 30-31, 2013. Adama, Ethiopia. International water Management Institute (IWMI).

Galvin A (2009) Transitions: pastoralists living with change. Annual Review of Anthropology 38, 185-198.

Gebremedhin B, Woldehanna M, Flintan F, Wieland B and Poole J (2017) Baseline Survey Report for the Regional Pastoral Livelihoods Resilience Project in Ethiopia. ILRI project report. Nairobi, Kenya: International Livestock Research Institute (ILRI).

German L, Mansoor H, Alemu G, Mazengia W, Amede T and Stroud A (2007) Participatory integrated watershed management: evolution of concepts and methods in an ecoregional program of the Eastern African highlands. Agricultural Systems 94, 189-204.

German L, Elizabeth G, Unks R and Wachira NP (2017) This side of subdivision: individualization and collectivization dynamics in a pastoralist group ranch held under collective title. Journal of Arid Environments 144, 139-155.

Getnet M, Amede T, Tilahun G, Legesse G, Gumma MK, Abebe H, Gashaw T, Keller C and Akker EV (2019) Water spreading weirs altering flood, nutrient distribution and crop productivity in upstream-downstream settings in dry lowlands of Afar, Ethiopia. Renewable Agriculture and Food Systems, 1-11.

Gummadi S, Rao KPC, Seid J, Legesse G, Kadiyala MDM, Takele R, Amede T and Whitbread A (2017) Spatio-temporal variability and trends of precipitation and extreme rainfall events in Ethiopia in 1980-2010. Theoretical and Applied Climatology 134, 1315-1328.

Gebre-Mariam A (1994) The pastoral land crisis: tenure and dispossession in Eastern Africa. Nomadic Peoples 34/35, 137-146.

Gina TG (2015) An appraisal on rangeland resources and its current status in Ethiopia: challenges and opportunities. International Journal of Emerging Technology and Advanced Engineering 5, 354-356.

GIZ KfW (2012) Water-spreading weirs for the development of degraded dry river valleys experience from the Sahel. Available at https://wocatpedia.net/ images/c/cb/GIZ\%2CKfW_\%282012\%29_Water-spreading_weirs_for_the_ development_of_degraded_dry_river_valleys.pdf.

Hardegree SP, Abatzoglou JT and Brunson MW (2017) Weather centric rangeland revegetation planning. Rangeland Ecology Management 71, 1-11.

Harwood R (2014) Capacity building vs. innovation readiness. Available at https://www.huffingtonpost.com/richard-c-harwood/capacity-building-vsinno_b_4596352.html.

Hillel D (2005) Water harvesting. Encyclopedia of Soils in the Environment, 264-270.

Hillel D (undated) Negev: land, water, and civilization in a desert environment. United Nations University. Available at http://archive.unu.edu/unupress/unupbooks/uu02fe/uu02fe05.htm.

Karl WJ, Herrick JE and Browning DM (2012) A strategy for rangeland management based on best available knowledge and information. Rangeland Ecology and Management 65, 638-646.

Louhaichi M, Ziadat F, Ates S and Zucca C (2016) Rangeland rehabilitation in southern part of the Mediterranean basin. Options Mediterraneennes 114, 415-418.
Lesorogol C (2008) Setting themselves apart: education, capabilities, and sexuality among Samburu women in Kenya. Anthropological Quarterly 81, 551-577.

Lind J, Sabates-Wheeler R, Kohnstamm S, Caravani M, Eid A, Nightingale DM and Oringa C (2016) Changes in the drylands of eastern Africa: case studies of pastoralist systems in the region. IDS- University of Sussex, UK.

Murali KG, Amede T, Getnet M, Pinjarla, B, Panjala, P, Legesse, G, Tilahun G, Van den Akker E, Berdel W, Keller C, Siambi M and Whitbread A (2019) Assessing potential locations for flood-based farming using satellite imagery: a case study in Afar region, Ethiopia. Renewable Agriculture and Food Systems (this volume).

Oweis T, Prinz D and Hachum YA (2012) Rainwater Harvesting for Agriculture in Dry Areas. London, UK: Balkema, Taylor and Francis, CRC Press.

Perrin B (2002) How to-and how not to-evaluate innovation. Evaluation 8, $13-28$.

Raymond E (2001) Cathedral and the Bazaar: Musings on Linux and Open Source by an Accidental Revolutionary, Revised Edn. Cambridge: O’Reilly Media.

Rettberg S (2010) The impact of sugarcane plantations on pastoral livelihoods within the Afar region of Ethiopia. In: Sugarcane and indigeneous people. Ethical sugars. pp. 7-12.

Sabyrbekov R (2019) Income diversification strategies among pastoralists in Central Asia: findings from Kyrgyzstan. Pastoralism 9, 14.

Schöning A, van den Akker E, Wegner M and Ackermann K (2012) Deutsche water-spreading weirs: improving resilience in dry areas. Available at http://www.tropentag.de/2012/abstracts/posters/714.pdf.

Solomon TB, Snyman HN and Smit GN (2007) Cattle-rangeland management practices and perceptions of pastoralists towards rangeland degradation in the Borana zone of southern Ethiopia. Journal of Environmental Management 82, 481-494.

Springer-Heinze A, Hartwich F, Henderson JS, Horton D and Minde I (2003) Impact pathway analysis: an approach to strengthening the impact orientation of agricultural research. Agricultural Systems 78, 267-285.

Statuto D, Cillis G and Picuno P (2016) Analysis of the effects of agricultural land use change on rural environment and landscape through historical cartography and GIS tools. Journal of Agricultural Engineering 47, 28-39.

Tsegaye D, Vedeldb P and Moe SR (2013) Pastoralists and livelihoods: a case study from northern Afar, Ethiopia. Journal of Arid Zone Environments 91, 138-146.

UNICEF (2017) Ethiopia annual report. Available at https://www.unicef.org/ about/annualreport/files/Ethiopia_2017_COAR.pdf.

van Steenbergen F, Haile AM, Alemehayu T, Almirew T and Geleta Y (2011) Status and potential of spate irrigation in Ethiopia. Water Resources Management 25, 1899-1913. doi: doi: 10.1007/s11269-011-9780-7.

Vanmaercke M, Abraha ZA, Poesen J, Nyseen J, Verstraeten G and Deckers J (2010) Sediment dynamics and the role of flash floods in sediment export from medium-sized catchments: a case study from the semi-arid tropical highlands in northern Ethiopia. Journal of Soils and Sediments 10, 611627. doi: DOI: $10.1007 / \mathrm{s} 11368-010-0203-9$.

Vetter S (2005) Rangelands at equilibrium and non-equilibrium. Journal of Arid Environments 62, 321-341.

Wilson JA (1982) The economical management of multi species fisheries. Land Economics 58, 417-434. 